\title{
Social Relationships and Relationships in Context: Post-Accession Poles in Southampton
}

\author{
Derek McGhee ${ }^{1, *}$, Paulina Travena ${ }^{2}$ and Sue Heath ${ }^{3}$ \\ ${ }^{1}$ University of Southampton, Centre for Population Change, Southampton, UK \\ ${ }^{2}$ Central and East European Studies, University of Glasgow, Glasgow, UK \\ ${ }^{3}$ Sociology, School of Social Sciences, The University of Manchester, Manchester, UK
}

\section{ABSTRACT}

In this article, we examine post-accession Poles' shifting identity practices through the lens of their attitudes to other Poles in a high-density post-accession Polish migration destination, namely the city of Southampton on England's south coast. We examine the impact of human capital (in this instance, we will focus on their ability to speak English) and the extent of their social capital (focusing on the restrictions based on their communicative competence with nonPolish groups and their particular trust issues associated with compatriots). We contextualise our findings in other research on post-accession Poles in London, Glasgow, the Midlands of England, the North of England, the Netherlands, Norway, and Brussels, thus drawing together common themes from a wide body of evidence. Through examining biographical data focusing on the everyday lives of our participants, we were able to explore the impact of context on their presentation of their identities and relational practices. By so doing, we exposed the interplay of a range of intersecting factors that result in many of our participants leading restrictive and restricted lives. (C) 2015 The Authors Population, Space and Place Published by John Wiley \& Sons Ltd.

Accepted 20 October 2014

Keywords: social capital; linguistic capabilities; Polish migrants; social networks

* Correspondence to: Derek McGhee, University of Southampton, Centre for Population Change, Southampton, UK.

E-mail: D.P.McGhee@soton.ac.uk

\section{INTRODUCTION}

I $\mathrm{n}$ this article, we will examine the impact of context on the relationship and network practices of post-accession Poles. Our analysis is influenced by Pred's $(1983,1984)$ insistence that the examination of individuals' relationships to place should include the analysis of both agency and structure and the external and internal factors that are observable in the mundane and everyday lives of individuals. In order to achieve this, we borrow from Kosic's (2006) approach for understanding the way that migrants construct their identities in particular contexts on a variety of levels including environmental conditions, social conditions, and particular constraint (2006: 262).

The structure of the article is as follows: In part 1, we review recent post-accession Polish research in the UK; in part 2, we explore particular environmental conditions, for example, our participants' preference for informal and instrumental engagement in the numerous 'Polish shops', and other amenities that have sprung up in Southampton since 2004. In part 3, we examine the impact of particular constraints on the 'integration' and 'social mobility' of some our participants in particular those with low 'host country' human capital (e.g., in terms of their linguistic competence). In part 4 , we will analyse the combined impact of social and environmental conditions, for example, our participants' perceptions of anti-migration attitudes in Southampton, as well as their suspicion of compatriots and the impact that these have on their relationship or network practices. We will examine the latter, following Ryan (2011), not in terms of taken for granted 'bonding' and 'bridging' networks, but rather through examining identities, relationships, trust, and the capacity to form networks. The argument that we make is that it is 
the combination of environmental (e.g., anti-Polish hostility and lack of 'integration' with established Polish churches and social clubs) and social conditions (co-ethnic suspicion and lack of trust and a preference for small-kinship-based sociality) and the presence of constraining factors (e.g., lack of linguistic competence) that leads to a number of our participants leading particularly restricted and restrictive lives in Southampton. Throughout the article, we build our argument through contextualising our findings in other post-accession Polish studies conducted in the North of England; the midlands of England, Glasgow, and London; the Netherlands; Norway; and Brussels. By contextualising our findings in the findings of other research on postaccession Poles in other parts of the UK and in other cities in Europe, we note that the impact of environmental conditions, social relationship practices, and particular constraints is not unique to Southampton. Furthermore, following Kosic, we do not equate our findings to group characteristics (e.g., in terms of their behaviour being influenced by dispositions and mentalities associated with 'post-socialist' subjects). Rather, what our findings reveal is adaptation to context, when particular environmental and social conditions are combined with low host country social capital especially amongst 'lower skilled' postaccession Poles.

\section{Part 1: Researching Post-Accession Poles in the UK}

The EU enlargement of 2004 was a highly consequential one for the UK. The opening of its labour market to nationals of accession eight (A8) countries resulted in one of the largest and most intensive migration flows in contemporary European history. This flow of migrants from A8 states has been described as 'one of the most important social and economic phenomena shaping the UK today' (Pollard et al., 2008: 7). Notably, the overwhelming majority of the new migrants had arrived from Poland (Home Office, 2009). The post-accession Polish 'community' thus appears to be the fastestgrowing migrant community in present-day Britain with Poles having become the single largest foreign national group resident in the UK (Office for National Statistics, 2011). This research is timely as there have been a number of contradictory media reports that suggest that (1) Poles are leaving the UK to return to Poland in the context of the economic downturn (e.g., Pidd, 2011) and (2) Poles are returning to the UK after failing to obtain employment in Poland (e.g., Gentleman 2011). Although this research was conducted during the economic downturn, we note that few of our interviewees are planning to return to Poland precisely because they find life 'easier' and affordable in the UK. Furthermore, most tell us that they have a better standard of living and higher quality of life in the UK compared with Poland even in the context of the economic downturn (McGhee et al., 2012b).

Despite Poles expressing considerably greater satisfaction with their standard of living in the national opinion polls in Poland five years after accession, Anne White urges researchers to be cautious of reading too much into these figures. White suggests that behind these figures and the transition to a market economy in Poland can be found a story of 'winners' and 'losers' in terms of regional economic disparities and urban and rural disparities within the regions (2011: 27-28). According to White, small and medium-size towns across Poland, especially those dependent on just one or two major factories, have proven to be the most vulnerable to unemployment (2011: 28). Significantly, most of the participants from our Southampton sample have migrated from small or medium towns (below 150,000 residents) from all over Poland (refer to Table 1 for biographical details of our participants). Therefore, returning to Poland, especially if this means returning to 'hometowns' in these regions, would come with considerable financial risks for many Poles currently living in the UK.

Our Economic and Social Research Council Centre for Population Change-funded research (RES-625-28-0001) is part of a growing body of research focusing on the experiences of post-accession Polish migrants living in the UK (e.g., Garapich, 2008; Garapich \& Eade, 2008, 2009; Ryan, 2008, 2010; White \& Ryan, 2008; Burrell, 2009; Garapich et al., 2009; Rabikowska \& Burrell, 2009; White, 2009, 2011; Galasińska, 2010; Gill, 2010; Rabikowska, 2010; Pietka, 2011; McGhee et al., 2012a). It foregrounds what Favell calls 'the human face of migration' (2008: 702) and what Burrell describes as the personal experiences' of A8 or post-accession migrants in the UK (Burrell, 2009: 12). Our focus here is on the everyday, ordinary activities of our participants' daily lives accumulated in the process of conducting biographical interviews with 23 post-accession Polish migrants in their homes in 


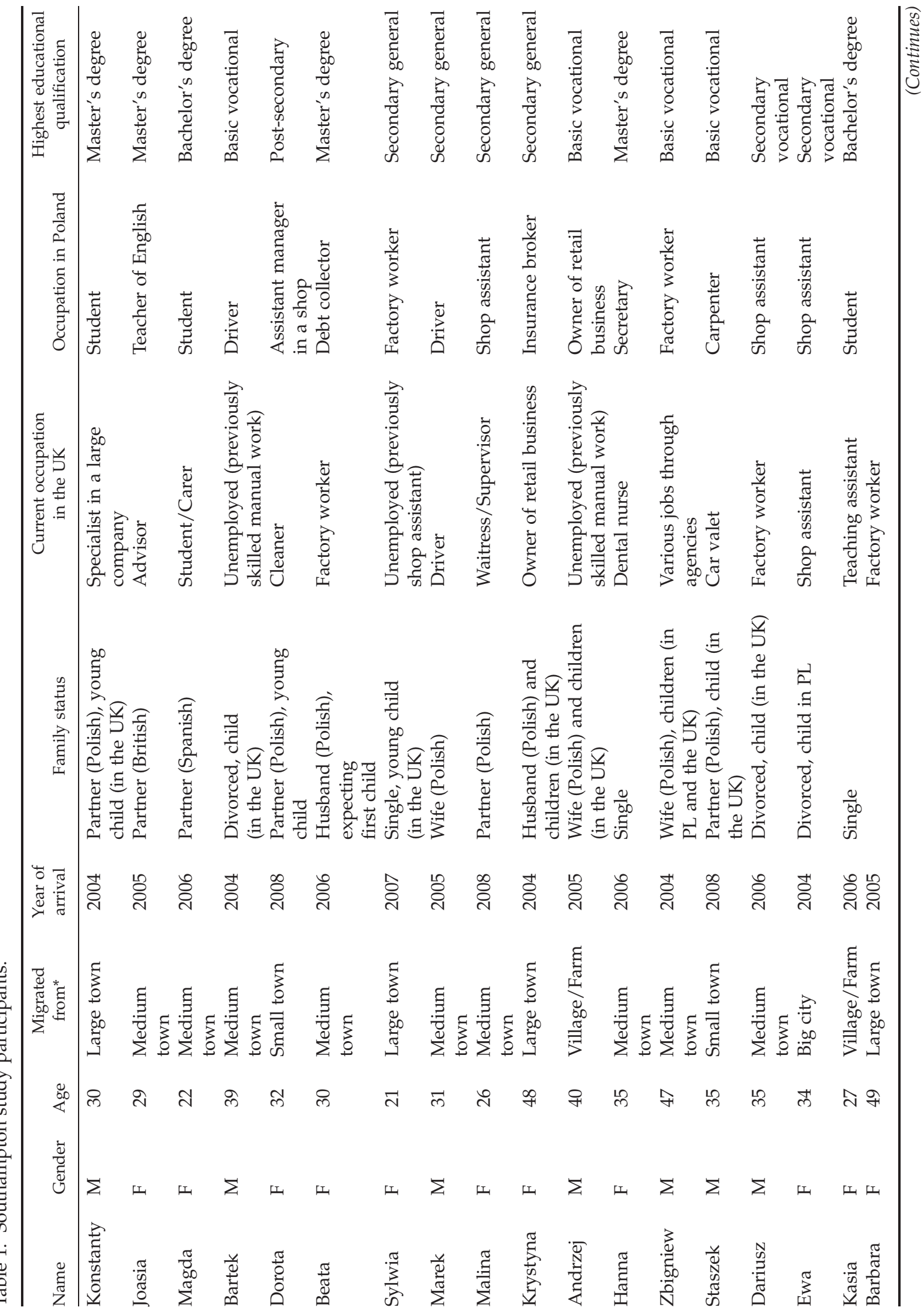




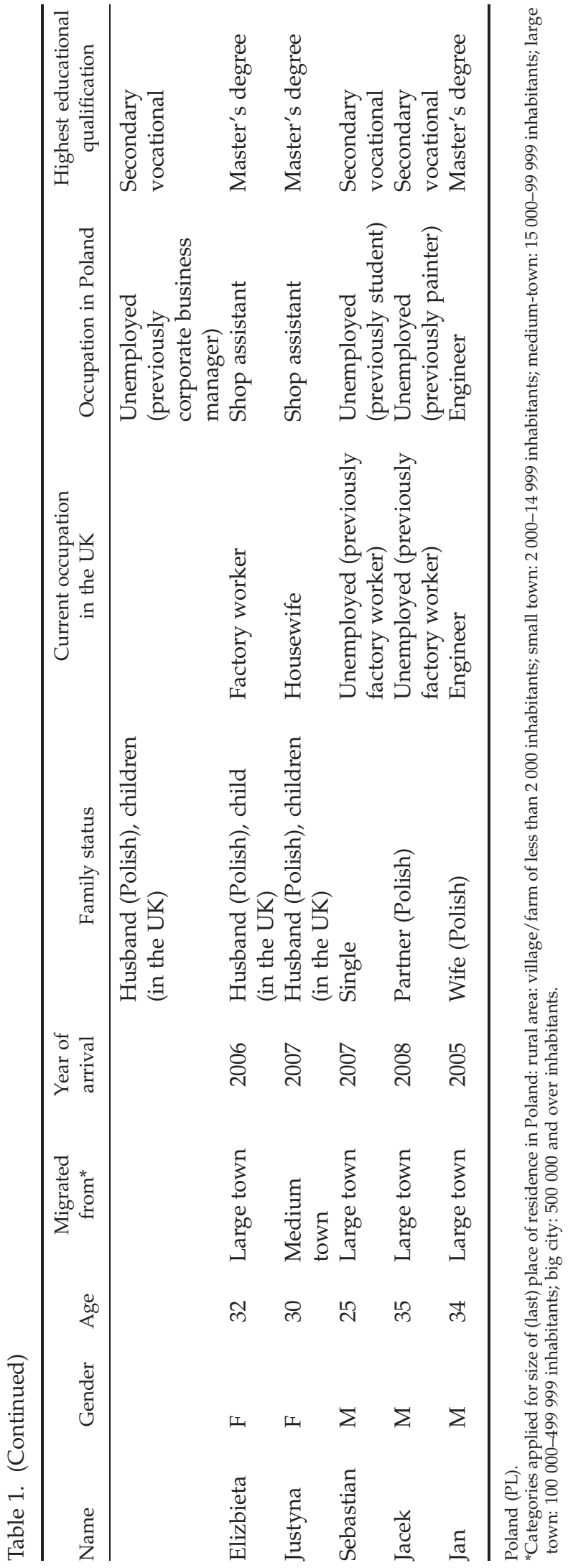

Southampton in 2010-2011. The target group was adult Poles who had arrived in the UK following Poland's EU accession in May 2004. We aimed to achieve a diversified sample in terms of family circumstances and household characteristics. We thus applied purposive sampling, aiming at a 50/50 gender split and 60/40 split of persons who had/do not have children. Moreover, participants were targeted according to household type, e.g. couples with and without children, living with relatives with and without children, living with friends with and without children, one-person households, and single-parent households. Study participants were recruited using a range of methods including advertisements on websites for Poles living in the UK, in local Polish shops and community places (including libraries and Polish clubs), through formal networks and organisations, and through personal networks and snowballing.

\section{Part 2: Environmental Conditions}

The city of Southampton in the centre of England's south coast has a long history of immigration that has been recently commemorated in a permanent exhibition in the SeaCity Museum, which was opened in 2012. Post-accession Polish migrants are the newest migrant group to be featured in this exhibition. According to the 2001 census, $89 \%$ of the population of Southampton was White British. This had fallen to $78 \%$ by the time of the 2011 census. The 'White other' population has increased by more than 200\% with 'European other' persons being counted at 17,004, with post-accession Poles being the largest group at 8,262 and Greeks the next biggest group at 538; other A8 and A10 countries mostly range from 99 to 310 population (Office for National Statistics, 2013). Southampton is therefore a high-density post-accession Polish destination and is therefore an ideal site for examining the practices, experiences, and perceptions of Poles.

This rise in the Polish-born population has, as it has in other parts of the UK, been complemented by a commercial or entrepreneurial response. Observations made by Rabikowska and Burrell in their study in London and also Galasińska in her study in the English Midlands concur with our observations in Southampton. Since 2004, there has been a marked increase in the entrepreneurial activities across the UK by new migrants, and the biggest expansion of all has been in Polish 
grocery shops (Rabikowska \& Burrell, 2009: 211). In this part, we will also examine the role of these Polish grocery shops in particular areas of Southampton (not to mention the availability of Polish hairdressers and mechanics) for facilitating a simulated (Gupta \& Ferguson, 1997:10) pluri-local sense of belonging 'here' and 'there' (Rouse, in Bammer 1992: ix) for our participants. As noted by Rabikowska and Burrell, in the case of migrants displaced from their homeland environments, material spaces of consumption, such as grocery shops, may serve as an 'ethnic marker' providing them with a sense of belonging (2009: 211). In this regard, we consider Brah's observation that migrants' narratives of feeling at home are often also a discourse of place and 'locality' (1996: 4). In our interviews, we noted that our participants were not beginning to feel at home in Southampton or Britain per se; rather, they are beginning to feel at home in the routines of their everyday lives, that is, mundane, 'localised, daily practices (Brah, 1996: 4, Gupta \& Ferguson, 1997: 11). For Brah, these practices can be experienced not only as both mundane but also (initially at least) as being unexpected for some migrants, for example, a number of our participants told us that they were surprised by how 'Polish' some of Southampton's neighbourhoods already were on their arrival. Many of our participants told us that they live and work with other Poles, they watch Polish TV, and more than that, they get their hair cut by Polish hairdressers and get their cars fixed and serviced by Polish mechanics. In terms of the emergence of the post-accession markers of Polish identities, one of our participants, Krystyna, refers to the area of Southampton where she lives and works as a 'Polish district':

Polish shops have appeared, Polish mechanics, Polish hairdressers, there's everything in this road. You can communicate in Polish in the bank, there are Poles everywhere. There are Poles in estate agents. The Angel Agency employs Poles. It has become a Polish District.

In many ways, these Polish venues and facilities supply the scenery or the scene for the site of habit' (Berger, 1984: 64). They provide 'some kind of ontological security in the context of migration' (Fortier, 2000: 163). Thus, what we note is that our participants' sense of belonging can be a matter of 'habit' (Berger, 1984) and routine (Giddens, 1991) associated with particular everyday practices and objects (Brah, 1996). The availability of food in Polish shops (rather than the availability of some Polish food in mainstream supermarkets) is particularly significant to the ease at which our interviewees seem to be able to 'dwell in displacement' and can begin to feel 'at home' in particular locations in the UK. Zbigniew declared the following: 'thank God for these Polish shops because we can't eat English food...because what is this English food? What can you cook?...since I've come here I only eat Polish food.' In many ways, the social space that is the 'Polish shop' can be conceptualised as the site of the convergence of objects and 'diasporic' subjects (Mankekar, 2005: 198). The availability of Polish bread, sugar, sausages, and over-the-counter medicines is significant for our participants because they 'facilitate the production of the modality of the familiar' (Mankekar, 2005: 201). Thus, Polish shops can be a nostalgic oasis for displaced people, who are provided with a 'Polish' experience, in terms of products, Polish signage, and hearing other Poles talking and indeed through the process of interacting with Polish shopkeepers (Rabikowska \& Burrell, 2009: 219).

Polish food, or what Hage calls 'home food', is a significant component in our participants' 'homebuilding' practices (Hage, 1997: 109). However, there is another side to all of this. Our participants did talk at length about feeling at home in these so-called 'Polish areas' where the Polish shops and other signs of 'Polishness' are located. However, they have had only sporadic (at Easter and Christmas) and in many cases no contact with the established Polish church in Southampton or the Polish social club, both of which were established by post-war Polish migrants and their descendants in particular areas of the city. A number of studies have examined the differences between established Poles and post-accession Poles in the UK. The former group has been described as 'ethnic community builders' in their attempts to 'establish a reputation, an image, or an idea of place that will afford political leverage in their struggles for recognition' (Gill, 2010: 1157). They achieved this through the introduction of institutions, spaces, and buildings that marked their presence and attempt to forge a collective community identity in Britain's towns and cities (Galasińska, 2010: 942). In contrast, a number of studies have maintained that postaccession Poles are not a 'cohesive' group and that concepts such as 'diaspora' and 'community' are misplaced when discussing this group (Gill, 2010; 
Garapich, 2008; Spencer et al., 2007; White \& Ryan, 2008). Furthermore, many post-accession Poles avoid established Polish institutions such as Polish churches and social clubs in the areas where they live in the UK (Galasińska, 2010; Gill, 2010). Our research in Southampton confirms this; only two of our participants (Beata and Justyna) were regular attenders of churches; a number of our participants told us that migration gave them the excuse to step away from church-related expectations and obligations (which were part of everyday life in some of the small towns and villages in Poland that they migrated from). For example, Konstanty told us that he and his partner have decided to start a family before marriage. For this reason, they sought out an English priest rather than a Polish priest to christen their child. Konstanty told us that he did this to avoid the scrutiny, pressure, and the potential upsetting confrontation that could ensue if they approached a Polish priest who in Konstanty's experience would hold very traditional views on marriage and family.

Gill suggests that facilities such as Polish grocery shops enable Poles to circumvent the established Polish institutions such as churches (2010: 1166). For Gill, Polish grocery shops, replete with wellinformed Polish shopkeepers, other shoppers, and also shop noticeboards, have become a crucial source of information and 'meeting places' for new migrant Poles (2010: 1166). What is important to note is that these activities, unlike the activities of the so-called ethnic community builders, might not accumulate and become institutionalised as identity markers. Torunczyk-Ruiz's research on Polish migrants in the Netherlands suggests that contemporary Polish migrants in Europe appear to be 'a new category of individualistic migrants' (2008: 61) who, as noted previously, many of whom, have a tendency to avoid formal Polish groups and institutions. Torunczyk-Ruiz observed that Polish migrants did indeed frequent Polish shops but only to buy Polish products or to seek practical help from a shopkeeper (the latter mostly applied to new arrivals) and that these were instrumental encounters rather than ways of trying to connect with 'fellow countrymen' (2008: 43). Rabikowska and Burrell observed something very similar in their research in London. Polish shops were used merely as 'a forum for exchanging small adverts and job offers'; however, they stipulate that 'using it as a meeting point for more meaningful social exchange is something which is more an aspiration than a reality' (2009: 219). So, despite these shops being described as 'the heart of
Polish life' by a number of participants in Rabikowska and Burrell's study (and in our study too), the reality was that the interactions in these establishments were often fleeting, impersonal, and highly individualised (2009: 219). The availability of Polish shops and other 'Polish friendly' services in the high-density postaccession areas of Southampton could give the impression of what Appadurai calls a landscape of group identity (1991: 192), but this is of a different order to the post-war Polish community's attempts to build enduring institutions for the purposes of 'carrying the torch of Polishness for generations to come' (Galasińska, 2010: 942). As will be noted in the next two parts, certain social network practices and constraints have a particular impact on our participants' ability to access and build relationships beyond their close and intimate social circle.

\section{Part 3 - Constraints and Social Conditions}

Drawing on Pred (1983, 1984), our approach to conceptualising place and understanding the context in which participants live and work necessitates the examination of individuals' everyday lives including the performance of mundane institutional practices associated with the family and associated intimate networks. Added to this, we are influenced by Massey's proposition that a place is formed out of the particular set of social relations that interact at a particular location (1994: 168). Their approaches have much sympathy with Kosic's (2006) multi-dimensional analysis for understanding the relationship between migrants' social identities in context, that is, the way migrants construct their identities in particular places. In this part, we will examine the combination of environmental conditions, our participants' relational and identification practices, and the constraining factors that they experience.

We have noted a particular tension associated with our participants' efforts (or more accurately capacity) to become more 'integrated' with what Fortier calls 'the hostland' (2000: 163). Sylwia is a prime example of a young woman living in one of the high-density post-accession Polish areas in Southampton. Sylwia told us that 'there are lots of Poles here. There aren't many English. Wherever you look there are Polish people'; it is for this reason that Sylwia feels at home in this district:

I feel at home here. Especially as there are so many Poles here. I feel like at home. I feel like 
in Poland, only you have to try to speak English from time to time.

Being able to communicate directly, in one's own language, in particular contexts is of utmost importance to our participants. Over $50 \%$ of our participants are not competent English speakers (although they were on the whole all multi-lingual). A number of our participants (e.g., Konstanty, Joasia, Jan, Magda, Justyna, and Elizbieta) are university graduates who are competent English speakers; their perceptions, relationships, and social mobility trajectories are significantly different to those participants with poor English language skills (especially when this is combined with secondary and vocational educational attainment). As in Ryan's (2011) research on highly qualified post-accession Poles in London, in our study, the graduates tended to live outside of the popular post-accession Polish districts; if their language skills allowed, they worked in professional jobs (with some exceptions, for example, Beata). For some of these participants, it was a case of dipping in and out of the popular Polish areas to buy food and get haircuts and cars serviced by Poles (out of habit). However, for the other participants, their experiences of being in Southampton is mediated through living in highdensity Polish areas and also often working with other Poles, and only occasionally having to venture outside of 'their Polish life' in terms of 'contact' with non-Poles. Furthermore, some of these participants mentioned that they felt unwelcome and discriminated against in Southampton and that they tried to keep their distance from British and other groups in their neighbourhoods because of fear of confrontations and actual violence. Some of our participants had internalised some of the hostility towards Poles in Southampton, which had impacted on their ability to engender a sense of belonging and feeling at 'home' in the UK. For example, Hanna told us that she finds it difficult thinking of the UK as her home because she has become aware in a number of contexts, but particularly at work, that she is 'treated differently than a British person'. For Hanna, it is the accumulation of these experiences of discrimination, which she says 'only a person who is being treated differently is able to sense' that has impacted on her ambiguity about the UK. For others, this internalisation was combined with their desire to halt the flow of Poles into the UK to reduce the potential for increasing the anti-Polish backlash and for reducing their competition for jobs in the context of the economic downturn. For example, Sebastian told us 'there is the problem with work, I need to work and I'm not too happy with what is happening here because wherever I go there's a lot of Poles and less and less work'.

The majority of our participants certainly did not intend a permanent move to the UK. Many of them have extended their stay in the UK because, for example, they did not wanted to disrupt their children's education (McGhee et al., 2012a); they have achieved a better quality of life in the UK (McGhee et al., 2012b), and they are able, often for the first time, to afford to live outside of extended family households through renting their own accommodation in the UK (McGhee et al., 2013). Our participants are much more settled than the young, free, and single 'circular' migrants depicted in studies published closer to the initial accession period (e.g., Eade et al., 2006 and Favell, 2008). However, this sense of lasting or prolonged temporariness (GrzymalaKazlowska, 2005) amongst our participants can have an impact on their investment in 'host-country-specific human capital' (Dustmann, 2003: 127). Our participants (mostly those with secondary and vocational education) suggested three barriers or obstacles to them increasing their English language competence: (1) lack of opportunities to practice speaking English; (2) long working hours, child care, and shift work all make it difficult to commit to regular English classes; and (3) embarrassment is also an issue; some participants do not want to speak English in case they made a mistake and were humiliated as a consequence. As noted previously, the lack of opportunities to speak and learn to speak English is also associated with a lack of investment associated with the supposed 'temporariness' of their stay in the UK. For some participants, there is no urgency for them to improve their ability to speak English because they can continue to get by without learning English, especially those who live in high-density Polish areas. The way Stanislaw reflects on his domestic life in Southampton is a good example of what a number of our participants told us:

$[\mathrm{H}]$ ere I sometimes forget I'm in England. The Polish TV plays a big role in this. And generally, the atmosphere in my neighbourhood is very Polish. And we have Polish food. It's like at home. 
Sebastian adds to this when he refers to his sense of disorientation when he walks down his street in a Polish and multi-ethnic area of Southampton:

[W]hen I'd go out on the street there was a Polish shop here and a Polish shop there, here people are talking in Polish. Sometimes I walk down the street and I don't know where I am, is this Poland? is this India? Or what, where is this England?

In many ways, our participants, like other new and established migrant groups in the city, are carving out their own spaces of belonging often in multi-ethnic neighbourhoods in British cities. However, in many respects, as Ryan et al. also found in their research on post-accession Poles in London, their communicative competence limits the extent to which they can mobilise social capital amongst non-Polish groups (Ryan, 2008: 677). The inability to communicate beyond superficial greetings and predictable interactions and exchanges means that post-accession Poles with low 'host country specific' human capital are highly dependent on other post-accession Poles for information, advice, and support.

However, our participants' social relationships with other migrant Poles can be somewhat restricted. In our interviews, we have come across a common discourse: A Pole abroad is a wolf to a Pole ('Polak Polakowi wilkiem', which is a paraphrase of the Latin proverb 'homo homini lupus', refer to TorunczykRuiz, 2008). This suspicion of other Poles is consistent with studies in Glasgow (Pietka, 20110) London (Eade et al., 2006; Ryan, 2008) in Lancashire (Gill \& Bialski, 2011), Brussels (Grzymala-Kazlowska), Norway (Friberg, 2012: 1598), and the Netherlands (Torunczyk-Ruiz, 2008). It is associated with what Pietka calls a dichotomous perception of other Poles amongst post-accession Poles (2011: 137). There is some debate in the studies based in London (e.g. Eade et al., 2006; White \& Ryan, 2008) as to whether this discourse reflects real experiences or a rhetoric of mistrust amongst migrants from post-socialist countries. However, Friberg's study in Norway in which he found 'almost everyone had stories to tell of exploitative recruiters, middlemen and housing agents within the Polish Community' (2012: 1598) is consistent with our findings. Just as in Pietka's (2011) research in Glasgow, any of our participants have extremely close and trustful relations with a small number of close family and friends that is contrasted with relationships based on suspicion and distance to other migrant Poles. This co-ethnic suspicion associated with the 'wolf abroad' rhetoric was for many of our participants, and also for participants in Friberg's study in Oslo, reinforced by their experiences. For example, Sebastian told us, 'here I have met too many deceptive, greedy...I don't know enough words to describe these Poles, but they are simply terrible, some of them are anyway'; similarly, Jacek told us, 'we haven't come across any good from Poles here...plenty of scumbags have come over here from Poland', and Andrzej's tales of being 'ripped off' and left destitute captures the experience of some participants, whose early arrival naivety and unfamiliarity with the UK were targeted by what he called 'predatory Poles'. Our findings correlate closely with Ryan's research that suggests that the extent of the antipathy towards other Poles was strongly correlated with participants' education level and competence as English language speakers. These characteristics were, in turn, correlated with the participants (in Ryan's and our own research) being dependent on strong, horizontal, and affective networks (Ryan, 2011: 711). For example, Andrzej told us that he knows many Poles in Southampton who do not admit that they are Polish because they are ashamed about the way other Poles, especially young males behave:

[T]hey get drunk and sing the Polish anthem in the streets. There are some stupid Poles in Southampton. They are usually the younger guys that have come here, they are stupid. They annoy us.

It is unlikely that a small qualitative study can definitively answer all the practice versus rhetoric questions associated with the 'wolf abroad' discourse. Rather, our interest in this paper is to examine the relational practices that could be influenced by such rhetoric. For example, Stanislaw, like many of our participants, has told us that he has adopted an explicitly selective (and self-protective) approach to interacting with other Poles in Southampton:

$[\mathrm{H}]$ ere I avoid contacts with Poles. Well. Maybe not so much avoid as don't look for such contacts. I don't endeavour to look for such contacts because I do not want to be let down. 
In our interviews, we note a complex discourse that combines class, taste, and respectability in our participants' denigration and wariness of fellow Poles (and in some case British people too). Garapich suggests that these 'class-related' forms of differentiation are intensified in the context of migration (2011: 8), and Lopez-Rodriguez takes this further by suggesting that following migration, migrants often experience 'class repositioning' (2010: 351). This is not just a matter of the disruption of the normative meaning of migrants' class position as a result of their unfamiliarity with the social structure of their host (Lopez-Rodriguez, 2010: 351). It is also a response to the social and occupation 'mixedness' of their post-migration milieu. Our participants often experience a disruption of their occupational identities in the UK. That is, we have noted that it is unusual for Poles to be working in an occupation in the UK that not only matches their qualification level but usually also does not match their occupations and what they are trained (and have experience) in doing in the Polish labour market (Table 1). As a consequence, they are living and working cheek by jowl with Poles (and in some cases British people) who they have, as a number of our participants have told us, 'nothing in common with', 'who are not on our wave length', and 'who let down the rest of us through their behaviour'. For example, Barbara, who finds herself working in a factory in the UK with other Poles, informed us:

[T]he majority of Poles here are waste [odpady]... the worst riffraff has come here, people for whom spending your free time means boozing, taking drugs... and running around with some fellas...I do not want to have such acquaintances.

In many ways, these sentiments are associated with identity-making processes in this particular high-density Polish context. They are an indication of the interplay of external structural factors and an 'internal' emotional response (Pred, 1984:286) that can have significant effects on individuals' relational dispositions and identities. It is important to note as suggested by Kosic that it is social context rather than specific group features that 'determines the evaluative flavour of any given group membership' (2006: 258). Furthermore, these evaluation practices are influenced as to whether the individual or individuals involved perceive their group identity to be 'enhancing or jeopardising' to their 'positive sense of self' (2006: 258). Rather than conceptualising these migrants as exhibiting particular dispositions, for example, those of 'the post-socialist subject', with associated internalised inferiority and superiority complexes relative to the West and associated attitudes to compatriots (Kurczewska, 2003), we focus instead on our participants' relational and identity practices as part of their adaptation to their context in high-density Polish areas. By so doing, what we have noted is that in their attempts to differentiate and distance themselves from other post-accession Poles, some of our participants are exhibiting a type of 'reverse cultural alienation' (Bryceson \& Vuorela, 2002: 20). This is the opposite to the 'assertive distinctiveness' that migrants can exhibit in their attempt to differentiate themselves from the 'host group' through idealising their own culture (Verkuyten, 1997, cited in Kosic, 2006: 260). Rather, reverse cultural alienation is associated with migrants' attempts to distinguish themselves from co-national migrants who they perceive as having less cultural and human capital than themselves (Bryceson \& Vuorela, 2002: 20). This is a coping strategy used by migrants who are attempting to distance and distinguish themselves from a group who is 'not valued by others' in their context (Branscombe et al., 1999: 38). These practices can lead to advantages and benefits, for example, they can lead to the development of close-knit networks that can be experienced as a source of support (Coleman, 1990) associated with migrant settlement practices (Lin, et al., 1981). However, these practices can also be associated with particular disadvantages too. For example, by relying too heavily on 'dense networks', individuals and families can also be restricting their access to alternative sources of information about employment and educational opportunities outside of the network (Portes, 2010: 37). That is, the 'network mediated benefits' beyond the immediate family and close circle of friends (2010: 36). Furthermore, these networks can be associated with 'levelling pressures' (Portes and Sensenbrenner, 1993) that can be experienced as a pressure to conform to the expectations of other group members.

What we have noted is that for many of our participants, their sense of place and belonging in the UK is tied up with the transplantation of close and intimate relationships from 'back home' into their new locations in the UK (Pietka, 2011: 136). Just as in Pietka's research in Glasgow, many of our participants in Southampton migrated with soon after or were re-united after a time with 
family members and close friends. It is this group that provides them with information, routes into employment, general support, and their 'social life' in Southampton. Furthermore, other research tells us that these types of networks can lead to an orientation towards more permanent settlement through 'making the migration experience easier to bear emotionally and thus easier to extend indefinitely' (White \& Ryan, 2008: 1499). Thus, our participants 'dwelling as a mobile habitat (Chambers, 1994: 4) can through the transplantation of intimate relationships become more settled. However, these transplanted relationships that provide our participants with a sense of place and belonging also have the potential for limiting some participants' 'integration' and social mobility in the longer term.

A common concern to emerge in 'community cohesion' discourse is that the 'social capital' resources of particular communities are too immersed in 'ethnic-specific networks'. This interpretation of post-accession Poles in Southampton would obscure the heterogeneity and social dynamics amongst this social group. Many postaccession Poles' settlement patterns (especially those with low host country human capital and secondary or vocational educational) could be more accurately described as being a complex heterogeneous mosaic of fragmented and alienated social groups articulated spatially in close-knit, kinship-based clusters. This is not just a contextual effect in terms of being 'a Southampton' phenomenon. Grzymala-Kazlowska has noted a very similar process in her research on migrant Poles in Brussels, where she suggests that 'kinship-based cooperation' has replaced 'general ethnic solidarity' amongst migrant Poles (2005: 690). In many ways, to take the 'social capital' theme a little further, some postaccession Poles could be even more 'impoverished' than other ethnic communities, as many of our participants do not seem to benefit from 'ethnic capital' in the form of the potential resources, knowledge, and shared experiences that are available within their wider ethnic group. This is a consequence of their avoidance of Polish churches, community clubs, and associated institutions, even including Polish Saturday Schools for their children (in some case, this was more a matter that the Saturday Schools in question are only cater-Cater for younger children). As Gill and Bialski also found in their research on post-accession Poles in the North of England, we have found that some post-accession
Poles' 'alienating suspicion' of other Poles and their lack of capacity for 'bridging' with non-Polish groups lead to a 'tyranny of microgeographies' and 'the happenstance of strong yet limited association ties' (Gill \& Bialski, 2011: 246). The consequence of which is that some of our participants could become trapped in their small social circles' groupenforced expectations (Portes, 1995: 12).

\section{CONCLUSION}

In this article, we have contextualised our findings in the numerous other studies on post-accession Poles across the UK and in other European contexts. This body of research indicates that the migrant identity forging activities of post-accession Poles is somewhat different from the 20th century Polish migrations to the UK. Our findings correspond with the findings of other studies in the UK and in Europe that vocational or secondary educated Polish migrants with low host country social capital in particular seem to exhibit a range of social identity practices that are directly related to their social context. That is, they can exhibit a suspicion of co-ethics, they often have a preference for close-knit associational ties, and many of them avoid collective 'community' institutions. Instead, they prefer impersonal interactions with informal or commercial Polish amenities that do not require formal membership. Furthermore, these social identity practices are negatively impacted upon by constraints, in particular, their lack of (linguistic) capacity for creating 'bridging' opportunities with non-Polish groups. The latter is compounded by many of our participants' perceptions of 'environmental conditions' in particular their perceptions of an anti-Polish backlash in their localities. This has resulted in an intensification of their reverse cultural alienation in terms of attempts to try and distance themselves from other Poles and keep their distance from non-Poles in their vicinity. Furthermore, what our research indicates, given that it was conducted seven years after accession, is that these are not the practices of newly arrived Polish migrants who have only been in the UK a few months or weeks. Many of our participants have lived in the UK for at least four years and longer at the time of the interview (Table 1). They are also not single adult economic migrants who are in the UK to earn money to send to their families back home'. Many of our participants have either started families here, have brought children over, or are planning to have children in the UK. 
We are aware that many of our participants' preference for intimate kinship-based networks could produce significant levels of trust and reciprocity amongst close-knit post-accession Polish groups. However, these dynamics could come with 'social costs' in terms of access to resources, information, and knowledge that could curtail their social mobility (as advocated by Putnam, 2000) and lead to the tyranny of group expectations (Portes, 1995). For this reason, we need to think about post-accession Poles in a slightly different way; they can be 'bonded' but not within homogeneous 'ethnic communities'. Many of them live amongst small, closeknit groups bounded by mutual suspicion and nuanced identification and disidentification practices premised on differentiation from coethnics. The latter must also be further differentiated in terms of class, language competence, and educational attainment. In this article, we have noted similarities between our research and other studies in a number of UK and other European contexts. The contribution that we make in this article is to examine what Kosic (2006) calls the variety of social (e.g., transplanted intimate networks and avoidance of established ethnic institutions and compatriots) and environmental conditions (e.g., being able to live in what they perceive as 'Polish districts' but in the context of perceived anti-migrant hostility) and constraints (e.g., low host-nation human capital/linguistic competence) that influence the different ways in which some migrants construct their social identities in particular places. Furthermore, we have noted that it is post-accession Poles with poor English language skills in combination with secondary and vocational educational attainment that tend to lead to the most restrictive and restricted lives in such contexts. There is now an array of studies from elsewhere in the UK and in Europe that concur with our findings; the common ground between this research and our research is that context matters. Rather than conceptualising the relational and identificational responses to context in terms of reified group dispositions (e.g., a postsocialist mentality), researchers might be better served by instead focusing on the contexts in which migrants find themselves and the combination of environmental and social conditions and constraints that they perceive, experience, and negotiate in their daily lives.

\section{REFERENCES}

Appadurai A. 1991. Global ethnoscapes: Notes and queries for a transnational anthropology. In Recapturing Anthropology: Working in the Present, Fox RG (ed.). School of American Research Press: Santa Fe, NM; 191-210.

Bammer A. 1992. Editorial: The question of 'home'. New Formations 17: vii-xi.

Berger J. 1984. And Our Faces, My heart, Brief as Photos. Bloomsbury: New York.

Brah A. 1996. Cartographies of Diaspora: Contesting Identities. Routledge: London and New York.

Branscombe NR, Ellemers N, Spears R, Doosje B. 1999. The context and content of social identity threat. In Social Identity, Ellemers N, Spears R, Doosje B (eds). Blackwell: Oxford; 35-58.

Bryceson D, Vuorela U. 2002. Transnational families in the twenty-first century. In The Transnational Family, Bryceson D, Vuorela U (eds). Berg: Oxford; 3-30.

Burrell K. 2009. Introduction. In Polish Migration to the UK in the New European Union after 2004, Burrell K (ed.). Aldershot: Ashgate; 1-22.

Chambers I. 1994. Migrancy, Culture, Identity. Routledge: London and New York.

Coleman J. 1990. Foundations of Social Theory. Harvard University Press: Cambridge, MA.

Dustmann C. 2003. Return migration, wage differentials, and the optimal migration duration. European Economic Review 47: 353-369.

Eade J, Garapich M, Drinkwater P. 2006. Class and Ethnicity: Polish Migrants in London. CRONEM: University of Roehampton.

Favell A. 2008 The new face of east-west migration in Europe. Journal of Ethnic and Migration Studies 36(5): 701-716.

Fortier AM. 2000. Migrant Belongings: Memory, Space $\mathcal{E}$ Identity. Berg: Oxford.

Friberg JH. 2012. The stages of migration: From going abroad to settling down: post-accession Polish workers in Norway. Journal of Ethnic and Migration Studies 38(10): 1589-1605.

Galasińska A. 2010. Gossiping in the Polish Club: An emotional coexistence of 'old' and 'new' migrants. Journal of Ethnic and Migration Studies 36(6): 939-951.

Garapich M. 2008. Odyssean refugees, migrants and power: Construction of the 'other' within the Polish community in the United Kingdom. In Citizenship, Political Engagement and Belonging: Immigrants in Europe and the United States, Reed-Danahay D, Brettlee C (eds). Rutgers University Press: New Brunswick, NJ; 124-144.

Garapich M. 2011. Transnationalism revisited - a decade of migration between Poland and the United Kingdom. Studia Migracyjne-Przeglad Polonijny XXXVII, z.1(139): 5-10. 
Garapich M, Eade J. 2009. Settling and surviving in London? The experience of Poles and other A8 migrants in a global city. In Accession and Migration: Changing Policy, Society and Culture in an Enlarged Europe, Eade J, Valkanova Y. (eds). Ashgate: Aldershot.

Garapich M, Drinkwater S, Eade J. 2009. Poles apart? EU enlargement and the labour market outcomes of immigrants in the UK. International Migration 47(1): 161-190.

Gentleman A. 2011. Going; home; the Polish migrants who lost jobs and hope in the UK. The Guardian, 6 April, http://www.guardian.co.uk/world/2011/ apr/06/uk-polish-migrants-lost-jobs-and-hope

Giddens A. 1991. Modernity and Self-Identity: Self and Society in the Late Modern Age. Polity Press: Oxford.

Gill N. 2010. Pathologies of migrant place-making: the case of Polish migrants in the UK. Environment and Planning A 42: 1157-1173.

Gill N, Bialski P. 2011. New friends in new places: network formation during the migration process among Poles in the UK. Geoforum 42: 241-249.

Grzymala-Kazlowska A. 2005. From ethnic cooperation to in-group competition - undocumented Polish workers in Brussels. Journal of Ethnic and Migration Studies 31(4): 675-697.

Gupta A, Ferguson J. 1997. Introduction. In Culture, Power, Place, Gupta A, Ferguson J (eds). Duke University Press: Durham, NC; 1-32.

Hage G. 1997. At home in the entrails of the West: Multiculturalism, ethnic food and migrant homebuilding. In Home/World: Space, Community and Marginality in Sydney's West, Grace H,Hage G, Johnson L, Langsworth J, Symonds G. (eds). Pluto Press: Annandale; 99-153.

Home Office. 2009. Accession Monitoring Report, May 2004-March 2009: A8 Migrants. Home Office: London.

Kosic A. 2006. Migrant identities. In Contemporary Polish Migration in Europe, Triandafyllidou A (ed.). Edwin Mellen Press: New York; 245-266.

Kurczewska J. 2003. What is likely to happen to Polish collective consciousness after accession to the European Union? Polish Sociological Review 1(141): 83-92.

Lin N, Ensel W, Vaugh J. 1981. Social resources and strength of ties: structural factors in occupational attainment. American Sociological Review 46: 393-405.

Lopez-Rodriguez M. 2010. Migrants and the quest for normalcy: Polish mothers and the quest for meritocratic opportunities in the UK. Social Identities 16(3): 339-358.

Mankekar P. 2005 'India shopping': Indian grocery stores and transnational configurations of belonging. In The Cultural Politics of Food and Eating, Watson JL, Caldwell ML (eds). Blackwell: Oxford; 197-214.

Massey D. 1994. Space, Place E Gender. Polity Press: Oxford.
McGhee D, Heath S, Trevena P. 2012a. Competing obligations and the maintenance of physical co-presence - the impact of migration and structural constraints on post accession Polish families in the UK. Families, Relationships E Society 2(2): 229-245.

McGhee D, Heath S, Trevena P. 2012b. Dignity, happiness and being able to live a 'normal life' in the UK an examination of post-accession Polish migrants' transnational autobiographical fields. Social Identities 18(5): 329-313.

McGhee D, Heath S, Trevena P. 2013. Post-accession Polish migrants - their experiences of living in 'low-demand' social housing areas in Glasgow. Environment and Planning A: 45: 329-343.

Office for National Statistics. 2011. Migration Statistics Quarterly Report November 2011 - Statistical Bulletin. http://www.ons.gov.uk/ons/rel/migration1/ migration-statistics-quarterly-report/november-2011/ msqr.html.

Office for National Statistics. 2013. Neighbourhood Statistics - Southampton Local Authority. http:// www.neighbourhood.statistics.gov.uk/dissemination/LeadTableView.do? $\mathrm{a}=7 \& \mathrm{~b}=6275251 \& \mathrm{c}=$ southampton $\& d=13 \& \mathrm{e}=13 \& \mathrm{~g}=6401303 \& \mathrm{i}=1001 \times 1003 \times 1004 \& \mathrm{~m}=0 \&$ $\mathrm{r}=1 \& \mathrm{~s}=1363099166152$ \&enc $=1$ \&dsFamilyId=2525.

Pidd H. 2011. Poland: Immigration to the UK is back for good life despite economic crisis. The Guardian, 27 May, http:/ /www.guardian.co.uk/world/2011/ may/27/poland-immigration-uk-economic-crisis.

Pietka E. 2011. Encountering forms of co-ethnic relations: Polish community in Glasgow. Studia Migracyjne Prezeglad Polonijy, Rok XXXVII Z.1(139): 129-152.

Pollard N, Lattore M, Sriskandarajah D. 2008. Floodgates or Turnstiles? Post-EU Enlargement Migration Flows to (and from) the UK. Institute for Public Policy Research: London.

Portes A. 1995. Economic sociology and the sociology of immigration: a conceptual overview. In The Economic Sociology of immigration, Portes A (ed.). Russell Sage Foundation: New York.

Portes A. 2010. Economic Sociology: a Systematic Enquiry. Princeton: Princeton University Press: NJ.

Portes A, Sensenbrenner J. 1993. 'Embeddedness and immigration: notes on the social determinants of economic action'. American Journal of Sociology 98: 1320-1351.

Pred A. 1983. Structuration and place: on the becoming of sense of place and structure of feeling. Journal for the Theory of Social Behaviour 13(1): 45-68.

Pred A. 1984. Place as historically contingent process: structuration and the time-geography of becoming places. Annals of the Association of American Geographers, 74(2): 279-297.

Putnam R. 2000. Bowling Alone; the Collapse and Revival of American community. Simon Schuster: New York. 
Rabikowska M. 2010. Negotiating normality and identity among migrants from Eastern Europe to the United Kingdom after 2004. Social Identities 16(3): 285-296.

Rabikowska M, Burrell K. 2009. The material worlds of recent Polish migrants: transnationalism, food shops and home. In Polish Migration to the UK in the New European Union after 2004, Burrell K (ed.). Aldershot: Ashgate; 211-232.

Ryan L. 2008. Social networks, social support and social capital - the experiences of recent Polish migrants in London. Sociology 42(4): 672-690.

Ryan L. 2010. Becoming Polish in London: negotiating ethnicity through migration. Social Identities 16(3): 359-376.

Ryan L. 2011. Migrants' social networks and weak ties: accessing resources and constructing relationships post-migration. Sociological Review 59(4): 707-724.
Spencer S, Ruhs M, Anderson B, Rogaly B. 2007. Migrants' lives beyond the Workplace. Joseph Rowntree Foundation: York.

Toruńczyk-Ruiz S. 2008. Being together or apart? Social networks and notions of belonging among recent Polish migrants in the Netherlands. CMR Working Papers, no. 40.98 .

White A. 2009. Family migration from Polish small towns to Western Europe: a livelihood strategy approach. In Polish Migration to the UK in the New European Union after 2004, Burrell K (ed.). Aldershot: Ashgate.

White A. 2011. Polish Families and Migration since EU Accession. Policy Press: Bristol.

White A, Ryan L. 2008. Polish 'temporary' migration: the formation and significance of social networks. Europe-Asia Studies 60(9): 1467-1502. 